\title{
RESEARCH
}

Open Access

\section{Diagnostic value of procalcitonin and presepsin for sepsis in critically ill adult patients: a systematic review and meta-analysis}

Yutaka Kondo ${ }^{1 \dagger}$, Yutaka Umemura ${ }^{2 \dagger}$, Kei Hayashida ${ }^{3 \dagger}$, Yoshitaka Hara ${ }^{4}$, Morio Aihara ${ }^{5}$ and Kazuma Yamakawa ${ }^{6 *}$ (D)

\begin{abstract}
Background: Early and accurate diagnosis of sepsis is challenging. Although procalcitonin and presepsin have been identified as potential biomarkers to differentiate between sepsis and other non-infectious causes of systemic inflammation, the diagnostic accuracy of these biomarkers remains controversial. Herein, we performed a comprehensive meta-analysis to assess the overall diagnostic value of procalcitonin and presepsin for the diagnosis of sepsis.

Methods: We searched three electronic databases (MEDLINE, EMBASE, and the Cochrane Central Register of Controlled Trials) for relevant studies. Two authors independently screened articles on the basis of inclusion and exclusion criteria. The pooled sensitivity, specificity, and summary receiver operating characteristic curves were estimated. The quality of evidence for diagnostic accuracy in absolute effects, i.e., the number of true or false positives and true or false negatives, gave a particular pre-test probability.

Results: We included 19 studies (19 observational studies and no randomized controlled trials) that had enrolled 3012 patients. Analyses of summary receiver operating characteristic curves revealed areas under the receiver operating characteristic curves of 0.84 for procalcitonin and 0.87 for presepsin. The pooled sensitivities and specificities were 0.80 ( $95 \%$ confidence interval 0.75 to 0.84 ) and 0.75 ( $95 \%$ confidence interval 0.67 to 0.81 ) for procalcitonin. For presepsin, these values were 0.84 ( $95 \%$ confidence interval 0.80 to 0.88 ) and 0.73 ( $95 \%$ confidence interval 0.61 to 0.82 ), respectively. There were no statistically significant differences in both pooled sensitivities $(p=0.48)$ and specificities $(p=0.57)$ between procalcitonin and presepsin.
\end{abstract}

Conclusion: Our meta-analysis provided evidence that the diagnostic accuracy of procalcitonin and presepsin in detecting infection was similar and that both are useful for early diagnosis of sepsis and subsequent reduction of mortality in critically ill adult patients.

Systematic review registration: The study was registered in PROSPERO under the registration number CRD42016035784.

Keywords: Sepsis, Procalcitonin, Presepsin, Diagnostic test accuracy, Systematic review, Meta-analysis

\footnotetext{
* Correspondence: k.yamakawa0911@gmail.com

†Yutaka Kondo, Yutaka Umemura and Kei Hayashida contributed equally to

this work.

${ }^{6}$ Division of Trauma and Surgical Critical Care, Osaka General Medical Center,

3-1-56 Bandai-Higashi, Sumiyoshi-ku, Osaka 558-8558, Japan

Full list of author information is available at the end of the article
}

(c) The Author(s). 2019 Open Access This article is distributed under the terms of the Creative Commons Attribution 4.0 International License (http://creativecommons.org/licenses/by/4.0/), which permits unrestricted use, distribution, and reproduction in any medium, provided you give appropriate credit to the original author(s) and the source, provide a link to the Creative Commons license, and indicate if changes were made. The Creative Commons Public Domain Dedication waiver (http://creativecommons.org/publicdomain/zero/1.0/) applies to the data made available in this article, unless otherwise stated. 


\section{Background}

Sepsis is defined as a life-threatening organ dysfunction caused by a dysregulated host response to infection [1]. Despite recent developments in the management of sepsis patients, morbidity and mortality still remain high [2]. Presently, clinical findings, biological markers, and microorganism isolation comprise the basis for diagnosing sepsis. Recent guidelines emphasize that early diagnosis and timely administration of antimicrobial therapy are crucial in reducing morbidity and mortality in sepsis patients [3]. However, no single clinical or biological marker indicative of sepsis has been adopted unanimously.

Procalcitonin (PCT) is the inactive propeptide of calcitonin, which is released by $\mathrm{C}$ cells of the thyroid gland, hepatocytes, and peripheral monocytes. PCT is widely reported as a useful biochemical marker to differentiate sepsis from other non-infectious causes of systemic inflammation. However, recent evidence has yielded conflicting results [4-6], which is reflected by the weak recommendation and the low quality of evidence in the 2016 Surviving Sepsis Campaign (SSC) guideline [3].

Presepsin (P-SEP), the newly identified infection biomarker, is a $13 \mathrm{kDa}$ fragment of the $\mathrm{N}$-terminal of soluble CD14 and is released into the blood upon the activation of monocytes in response to infection [7-10]. Although P-SEP appeared to be comparable to other inflammatory biomarkers, i.e., C-reactive protein, interleukin-6, and PCT, in the diagnosis of sepsis [11], there has been limited meta-analytical evidence on the diagnostic performance of P-SEP with PCT.

We thus sought to summarize the current clinical evidence regarding the diagnostic test accuracy (DTA) for PCT and P-SEP and analyze the diagnostic performance of both biomarkers in distinguishing sepsis from non-infectious inflammation in the critical care setting more comprehensively.

\section{Methods}

\section{Protocol registration}

This study complied with the recommendations for the conduct and reporting of systematic reviews and meta-analyses, set forth by the Preferred Reporting Items for Systematic Reviews and Meta-Analyses (PRISMA) statement [12-14], the Meta-Analysis of Observational Studies in Epidemiology proposal [15], and the Cochrane Diagnostic Test Accuracy Working Group [16]. We developed a protocol before conducting the analysis and registered it in PROSPERO (an international prospective register of systematic reviews [http://www.crd.york.ac.uk/PROSPERO/; Registration No. CRD42016035784]). The protocol for this study has been published previously [17].

\section{Focused review questions}

Primary objective: To determine the accuracy of PCT and P-SEP in diagnosing bacterial infection in critically ill adult patients.

Secondary objective: To determine which marker is superior in the diagnosis of bacterial infection in critically ill adult patients.

\section{Search strategy}

We searched the following databases for relevant studies: MEDLINE (via PubMed), EMBASE, and the Cochrane Central Register of Controlled Trials. We developed a search strategy using the combination of keywords and Medical Subject Heading (MeSH)/EMTREE terms, which were "(procalcitonin OR PCT OR presepsin OR "soluble CD14 subtype" OR "sCD14-ST" OR P-SEP) AND (sepsis OR "bacterial infection" OR "systemic inflammatory response syndrome" OR SIRS)." Searches of gray literature and bibliographies of relevant papers were used to complement the results of the search strategies. We did not apply any language restriction to the electronic searches. We also contacted the authors of ongoing or unpublished trials to obtain additional details and information on these trials.

\section{Inclusion and exclusion criteria}

Two investigators ( $\mathrm{YK}$ and $\mathrm{YH}$ ) conducted the study selection independently. Any disagreement was resolved by discussion and the participation of a third author (KY), when necessary. We included cross-sectional studies, cohort studies, case-control studies, and randomized controlled trials that evaluated the accuracy of PCT or P-SEP in plasma or serum (index test), when used to diagnose bacterial infection or sepsis in critically ill adult patients (reference standards). In this study, "sepsis" meant "life-threatening organ dysfunction caused by a dysregulated host response to infection," according to the new definition proposed in 2016 (Sepsis-3) [1]. We also accepted various comparable definitions, such as the severe sepsis/septic shock, with the conventional definition (Sepsis-1, 2) [18]. We excluded the following studies with insufficient information when building a $2 \times 2$ contingency table: abstracts with inadequate information to enable the assessment of methodological quality and duplicates or sub-cohorts of already published cohorts. We also excluded all studies investigating animals; those predominantly comprising neonates or post-cardiac surgical, heart failure, or perioperative patients; and those comprising healthy participants as controls.

\section{Data extraction and synthesis}

The characteristics of all included studies were extracted by two authors ( $\mathrm{YK}$ and $\mathrm{YH}$ ). We used $2 \times 2$ tables to cross-tabulate the positive or negative numerical data 
from the index test results (positive or negative) against the target disorder. We displayed all the results in various tables. To visually assess the between-study variability, we presented the results in a forest plot, as well as with summary receiver operating characteristic curves (sROC) with 95\% confidence interval (CI) using the MIDAS module in STATA software, V.14.0 (Stata Corporation, College Station, Texas, USA). Furthermore, we generated a Fagan's nomogram, which is a userfriendly graphical depiction of the positive/negative likelihood ratio (LR) by prevalence. Statistical heterogeneity was evaluated informally from the forest plots of the studies' estimates and more formally using the $\chi^{2}$ test $(p<0.1$, significant $)$ and $I^{2}$ statistic $\left(I^{2}>50 \%=\right.$ significant) with $95 \% \mathrm{CI}$.

We conducted sensitivity analyses to determine the robustness of the meta-analyses and to explore the sources of potential heterogeneity in sensitivity and specificity. We performed univariate meta-regression analysis using the following as covariates with 95\% CI: risk of bias, year of publication (after 2016 or before 2015), prevalence $(<50 \%$ or $\geq 50 \%)$, sample size $(<100$ or $\geq 100)$, setting (inside ICU or outside ICU), comorbidities (whether the studies excluded patients who had comorbidities that were likely to influence P-SEP levels), clinical diagnostic criteria (Sepsis-1, 2, or Sepsis-3), causal pathogens of infection (bacteria only or mixed with fungal, viral, or other pathogens), and the cutoff values for each biomarker ( $<1.0$ or $\geq 1.0$ for PCT, $<500$ or $\geq 500$ for P-SEP).

\section{Assessment of risk of bias}

The qualities of the included studies were independently assessed by two authors (YK and $\mathrm{YU}$ ) and verified by a third author (KY), when necessary. The study quality of each article was reported using the Quality Assessment of Diagnostic Accuracy Studies (QUADAS-2) tool [19]. We specifically assessed the presence of spectrum, threshold, disease progression, and partial or differential verification bias.

\section{Rating of the quality of effect estimates}

We applied the Grading of Recommendations Assessment, Development, and Evaluation (GRADE) approach to rate the quality of the evidence [20]. The quality of evidence, which reflects the extent to which we are confident that an estimate of the effect is correct, is rated for each outcome across studies (i.e., for a body of evidence). Although the quality of evidence represents a continuum, the GRADE approach provides the rating for the quality of the body of evidence in one of the four grades: high, moderate, low, or very low, defined as follows:
- High: We are very confident that the true effect lies close to that of the effect estimate.

- Moderate: We are moderately confident of the effect estimate and that the true effect is likely to be close to the effect estimate, but there is a possibility that it is substantially different.

- Low: Our confidence in the effect estimate is limited, such that the true effect may be substantially different from the effect estimate.

- Very low: We have very little confidence in the effect estimate, such that the true effect is likely to be substantially different from the estimate of effect.

Confidence ratings may decrease when there is increased risk of bias, inconsistency, imprecision, indirectness, or concern about publication bias.

In contrast to the therapeutic intervention, the GRADE approach suggests different criteria when the evidence comes from studies on diagnostic accuracy. Valid diagnostic accuracy studies-cross-sectional or cohort studies, in patients with diagnostic uncertainty, and in direct comparison of test results with an appropriate reference standard-provide high-quality evidence. However, they are often downgraded to lower quality evidence, because they are liable to limitations, particularly indirectness of outcomes, i.e., uncertainty about the link between the test accuracy and outcomes that are important to patients.

For each outcome, the quality of evidence was started on a high grade, became downgraded by one level when there was a serious issue identified, and by two levels when there was a very serious issue identified in each of the factors used in judging the quality of evidence.

\section{Importance of DTA outcomes}

In DTA, the importance of outcomes, including absolute effects (true positive, true negative, false positive, or false negative), was ranked according to their importance in decision-making as follows: critical, important, or of limited importance. We ranked all four outcomes as critical because both accurate diagnosis and misdiagnosis could influence mortality in critically ill patients.

\section{Results}

\section{Results of the search}

We identified 4203 potentially eligible articles at the initial search (Fig. 1), of which 4192 articles were retained after de-duplicating. After screening the titles and abstracts, 4031 articles were found to be clearly irrelevant and were excluded. We retrieved the full texts of the remaining 160 records (155 observational studies and 5 randomized controlled trials) and assessed them for eligibility. Finally, we included 19 studies (19 observational studies and no randomized controlled trials) that enrolled 3012 patients [11, 


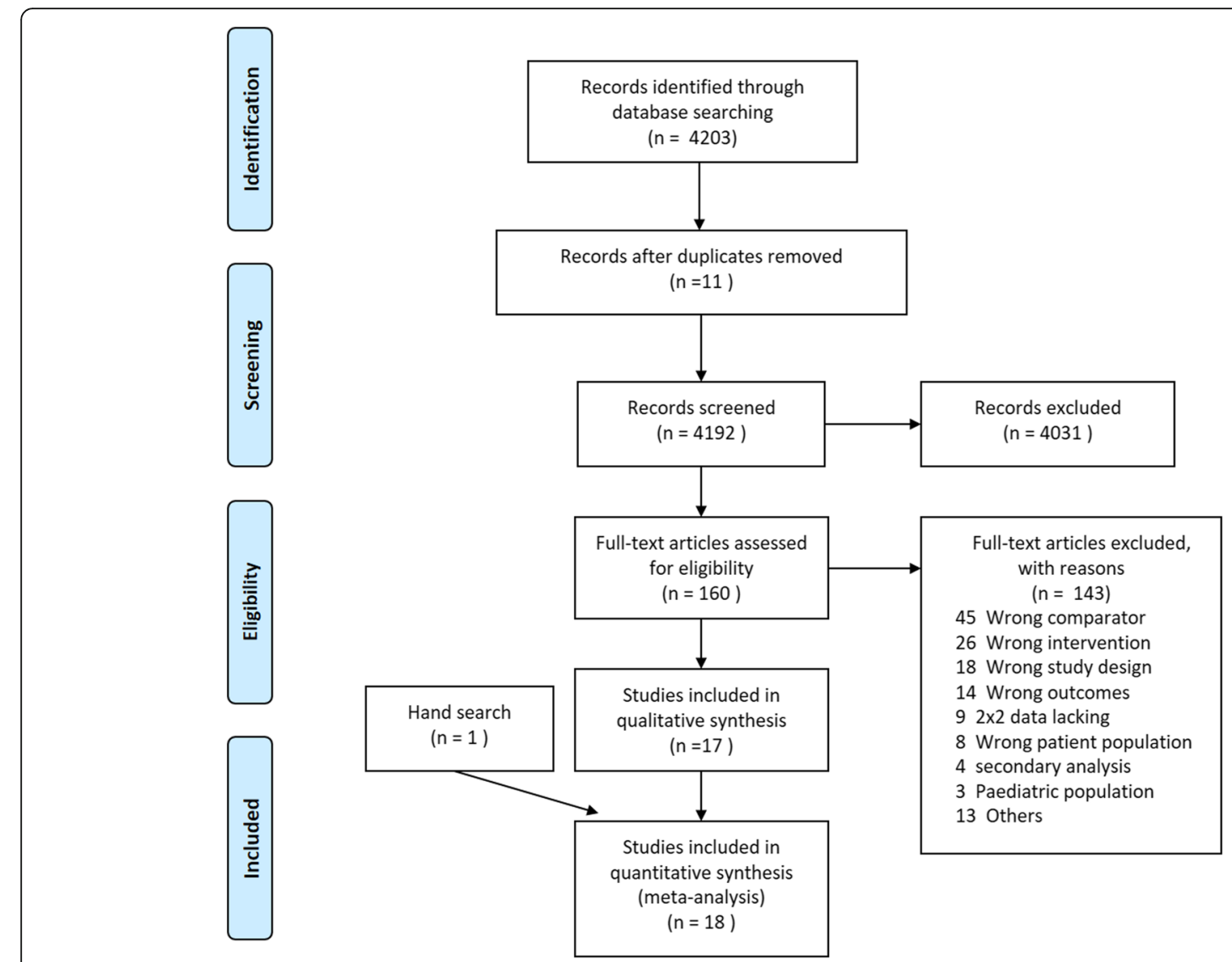

Fig. 1 Flow chart of the identification and selection of studies for inclusion

21-37]. Among these, 18 [11, 21-23, 25-37] studies evaluated the diagnostic values of PCT in infection and 10 $[11,21,24-26,28-30,33]$ determined the diagnostic accuracy of P-SEP in infection.

\section{Basic features of included studies}

The characteristics of the included studies are summarized in Table 1. The earliest article [34] was published in 1999 while 18 were published after 2000, with 15 [11, 21, 23-26, 28-31, 33, 35-37] being published after 2010. Twelve studies [24, 26-32, 34-36] took place in Europe, 5 in Asia [11, 22, 25, 33, 37], and 1 each in North America [23] and Africa [21]. Seventeen [11, 21-27, $29,30,32-37$ ] studies were conducted prospectively, and the others were retrospective. All studies described diagnostic cutoff thresholds for PCT or P-SEP. The cutoff thresholds widely varied between $>0.28$ and $>4.5 \mathrm{ng} / \mathrm{ml}$ for PCT and between $>101.6$ and $>1000 \mathrm{pg} / \mathrm{ml}$ for P-SEP.

\section{Risk of bias of included studies}

We illustrated the quality of the included 19 studies using the QUADAS-2 tool (Fig. 2). All studies had unclear or high risk of bias in at least one domain. Five studies [11, 21, 28, 29, 32] demonstrated unclear or high-risk patient selection bias, resulting mainly from inappropriate exclusion criteria and the absence of a clear definition for exclusion criteria. All studies demonstrated unclear or high risk of index test interpretation bias, owing to the lack of a clearly pre-specified cutoff threshold of PCT and P-SEP for a positive diagnosis.

We assigned a high concern for patient selection applicability in four studies [11, 22, 25, 36], which included critically ill adult patients, regardless of suspected bacterial infection. Only one study [25] focusing on severe burn patients was assigned an unclear concern for applicability with respect to the index test, because burns could be a possible source of increased PCT and P-SEP levels. None of the studies had high or unclear concerns for applicability with respect to the reference standard.

\section{Diagnostic accuracy}

The forest plot in Fig. 3 shows the sensitivity and specificity ranges for PCT and P-SEP for infection, across included studies. The pooled sensitivity for PCT and P-SEP were 0.80 (95\% CI 0.75 to 0.84 ) and 0.84 (95\% CI 0.80 to 0.88$)$, respectively. The pooled specificities of these biomarkers were 0.75 for the former $(95 \%$ CI 0.67 to 0.81 , for $\mathrm{PCT})$ and 0.73 for the latter $(95 \% \mathrm{CI} 0.61$ to 
Table 1 Characteristics of the included studies

\begin{tabular}{|c|c|c|c|c|c|c|c|c|c|c|c|c|}
\hline \multirow[t]{2}{*}{ Author, year } & \multirow[t]{2}{*}{ Country } & \multirow{2}{*}{$\begin{array}{l}\text { Number of } \\
\text { participants }\end{array}$} & \multirow{2}{*}{$\begin{array}{l}\text { Mean/ } \\
\text { median } \\
\text { age }\end{array}$} & \multirow[t]{2}{*}{ Study design } & \multirow{2}{*}{$\begin{array}{l}\text { Sepsis } \\
\text { definition }\end{array}$} & \multicolumn{2}{|c|}{ Cutoff value } & \multirow[t]{2}{*}{ Prevalence } & \multicolumn{2}{|c|}{ Sensitivity } & \multicolumn{2}{|c|}{ Specificity } \\
\hline & & & & & & $\begin{array}{l}\mathrm{PCT} \\
(\mathrm{ng} / \mathrm{ml})\end{array}$ & $\begin{array}{l}\text { P-SEP } \\
(\mathrm{pg} / \mathrm{ml})\end{array}$ & & PCT & P-SEP & $\mathrm{PCT}$ & P-SEP \\
\hline Ali, 2016 [21] & Egypt & 51 & 49.8 & Prospective & Sepsis-3 & 0.85 & 907 & 0.647 & $60.6 \%$ & $69.7 \%$ & $88.9 \%$ & $83.3 \%$ \\
\hline Balci, 2003 [22] & Turkey & 89 & 58 & Prospective & Sepsis-1 & 2.415 & - & 0.461 & $85.4 \%$ & - & $91.7 \%$ & - \\
\hline Bauer, 2016 [23] & USA & 219 & 59 & Prospective & Sepsis-1 & 0.74 & - & 0.551 & $73.1 \%$ & - & $74.2 \%$ & - \\
\hline Behnes, 2014 [24] & Germany & 116 & 62 & Prospective & Sepsis-2 & - & 530 & 0.705 & - & $91.0 \%$ & - & $53.6 \%$ \\
\hline $\begin{array}{l}\text { ÇakirMadenci, } \\
2014 \text { [25] }\end{array}$ & Turkey & 37 & 40 & Prospective & ABA $2007^{\mathrm{a})}$ & 0.759 & 542 & 0.393 & $75.4 \%$ & $77.5 \%$ & $78.7 \%$ & $76.5 \%$ \\
\hline Endo 2012 [11] & Japan & 185 & 66 & Prospective & Sepsis-2 & 0.5 & 600 & 0.622 & $86.1 \%$ & $87.8 \%$ & $78.6 \%$ & $81.4 \%$ \\
\hline $\begin{array}{l}\text { Enguix-Armada } \\
2016 \text { [26] }\end{array}$ & Spain & 388 & 63 & Prospective & Sepsis-2 & 0.28 & 101.6 & 0.634 & $92.3 \%$ & $81.7 \%$ & $96.5 \%$ & $96.5 \%$ \\
\hline Gibot 2004 [27] & France & 76 & 60 & Prospective & Sepsis-1 & 0.6 & - & 0.618 & $83.0 \%$ & - & $69.0 \%$ & - \\
\hline Godnic 2015 [28] & Slovenia & 47 & N.A. & Retrospective & Sepsis-2 & 3.12 & 413 & 0.851 & $57.5 \%$ & $85.0 \%$ & $71.4 \%$ & $57.1 \%$ \\
\hline Klouche 2016 [29] & France & 144 & 58 & Prospective & Sepsis-1 & 0.5 & 466 & 0.694 & $80.0 \%$ & $90.0 \%$ & $59.1 \%$ & $54.5 \%$ \\
\hline Leli 2016 [30] & Italy & 92 & 73 & Prospective & Sepsis-1 & 4.4 & 843.5 & 0.281 & $84.0 \%$ & $88.0 \%$ & $84.4 \%$ & $71.9 \%$ \\
\hline Miglietta 2015 [31] & Italy & 145 & 64.4 & Retrospective & Sepsis-1 & 0.88 & - & 0.625 & $85.7 \%$ & - & $83.3 \%$ & - \\
\hline $\begin{array}{l}\text { Romualdo } \\
2014\end{array}$ & Spain & 226 & 67 & Prospective & Original & 0.45 & 729 & 0.164 & $75.7 \%$ & $81.1 \%$ & $64.0 \%$ & $63.0 \%$ \\
\hline Selberg 2000 [32] & Germany & 33 & 47.9 & Prospective & Sepsis-1 & 3.3 & - & 0.667 & $86.4 \%$ & - & $54.5 \%$ & - \\
\hline $\begin{array}{l}\text { Takahashi } \\
2016 \text { [33] }\end{array}$ & Japan & 103 & 68 & Prospective & Sepsis-1 & 0.85 & 658 & 0.85 & $78.8 \%$ & $72.9 \%$ & $73.3 \%$ & $60.0 \%$ \\
\hline Ugarte 1999 [34] & Belgium & 190 & 62 & Prospective & Sepsis-1 & 0.6 & - & 0.584 & $67.6 \%$ & - & $60.8 \%$ & - \\
\hline $\begin{array}{l}\text { vanderGeest } \\
2016 \text { [35] }\end{array}$ & Netherlands & 301 & 57 & Prospective & Original & 1.41 & - & 0.505 & $65.1 \%$ & - & $66.4 \%$ & - \\
\hline Wong 2013 [36] & France & 270 & 61 & Prospective & Not described & 0.5 & - & 0.537 & $88.3 \%$ & - & $64.0 \%$ & - \\
\hline Yang 2016 [37] & China & 300 & 64 & Prospective & Sepsis-1 & 0.4475 & - & 0.357 & $83.2 \%$ & - & $53.9 \%$ & - \\
\hline
\end{tabular}

PCT procalcitonin, P-SEP presepsin

${ }^{a)}$ American Burn Association Consensus Criteria

0.82, for P-SEP). Fagan's nomogram results for PCT indicated that the pooled pre-test probability ratio of $50 \%$ by positive/negative LR yielded positive/negative posttest probability ratio of $77 \%$ and $22 \%$, respectively. Furthermore, Fagan's nomogram results for P-SEP demonstrated positive/negative post-test probability ratio of $76 \%$ and $19 \%$, respectively. More details can be found in Additional file 1: Figure S1.

We also constructed the sROC curves and calculated the area under ROC (AUROC) for included studies (Fig. 4). The overall diagnostic performance of PCT and P-SEP for infection were comparable (AUROC 0.84 [95\% CI 0.81 to 0.87], and 0.87 [95\% CI 0.84 to 0.90], respectively).

\section{Investigations of heterogeneity}

Because there were substantial heterogeneities among pooled results of sensitivity and specificity for both PCT and P-SEP (Fig. 3), we performed several sensitivity analyses to explain the heterogeneities by investigating the study characteristics using meta-regression analysis.
Univariate meta-regression analysis revealed that the sensitivity of heterogeneity among included studies might be attributable to several relevant factors, such as the risk of bias (low risk or high risk), publication years (until 2015 or after 2015), prevalence of infection $(<50 \%$ or $\geq 50 \%)$, sample size $(<100$ or $\geq 100)$, study setting (inside ICU or outside ICU), clinical diagnostic criteria (sepsis-1, 2 or sepsis-3), and the cutoff value for each biomarker $(<1.0$ or $\geq 1.0$ for $\mathrm{PCT},<500$ or $\geq 500$ for P-SEP) (Fig. 5).

\section{Head-to-head comparison of the two biomarkers}

To compare the diagnostic performance of PCT and P-SEP in similar populations, we evaluated the nine studies which directly compared PCT and P-SEP in the same population [11, 21, 25, 26, 28-30,33]. As a result, there were no statistically significant differences in both pooled sensitivities $(p=0.48)$ and pooled specificities $(p=0.57)$ between PCT and P-SEP. Besides, we conducted a head-to-head comparison of PCT and P-SEP in several subgroups stratified by study characteristics and found no 


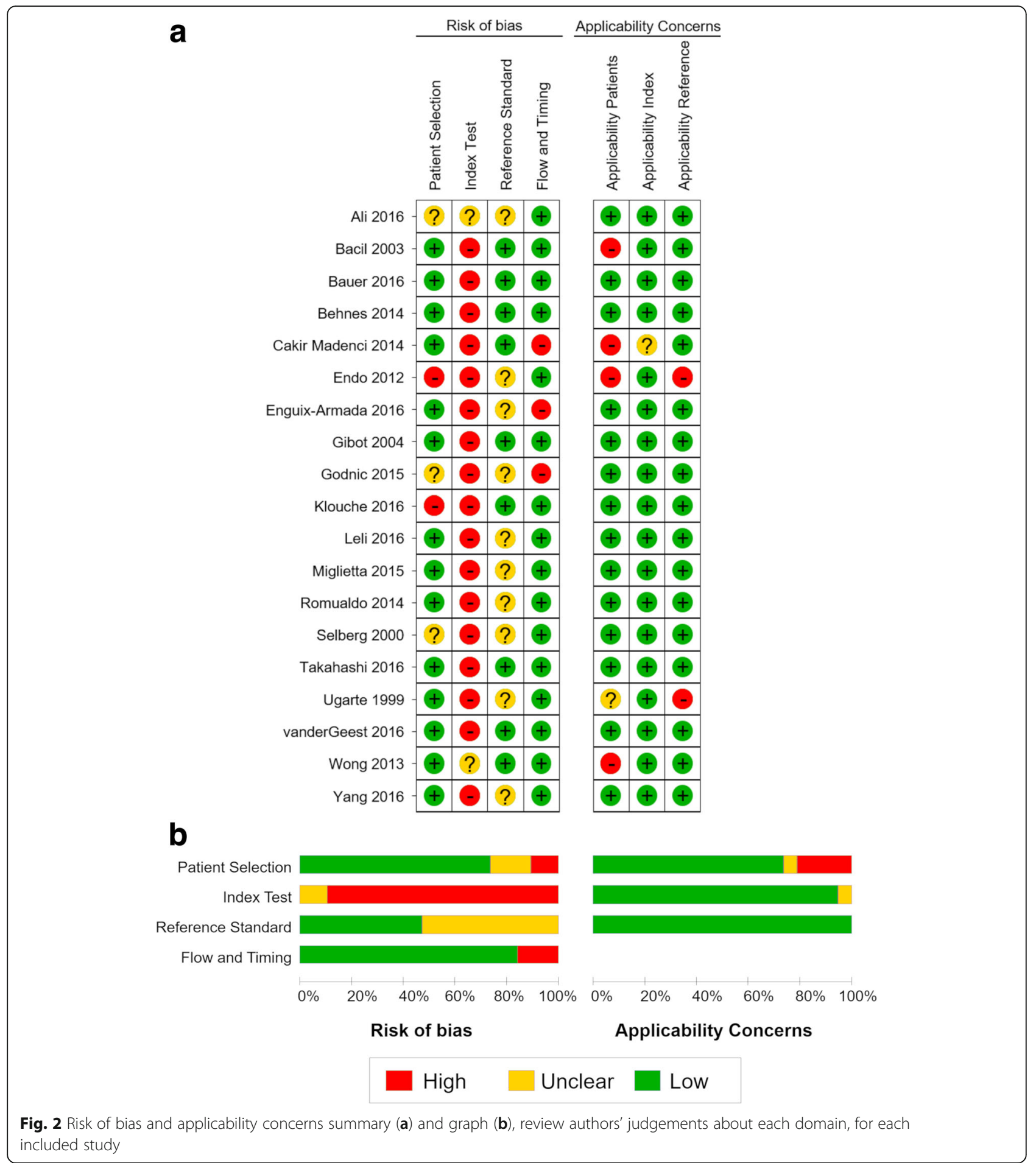

statistically significant differences between the two biomarkers in any of the subgroups (Additional file 2).

\section{Publication biases}

We detected no evidence of publication biases, assessed by Deeks' Funnel Plot Asymmetry Test (PCT: $p=0.67$, P-SEP: $p=0.35$ ) (Fig. 6).
Quality of DTA evidence using the GRADE system (or approach)

We summarized the main findings and the quality of evidence for each outcome across all the studies in the GRADE evidence profile (Table 2). Because, all included studies showed unclear or high risk of index test interpretation bias, the quality of evidence of the outcomes 


\begin{tabular}{|c|c|c|c|c|}
\hline \multicolumn{5}{|l|}{ PCT } \\
\hline Author year & SENSITIVITY $(95 \% \mathrm{CI})$ & SPECIFICITY $(95 \% \mathrm{Cl})$ & \multirow{2}{*}{ SENSITIVITY $(95 \% \mathrm{CI})$} & SPECIFICITY $(95 \% \mathrm{CI})$ \\
\hline Ali 2016 & $0.61[0.42-0.77]$ & $0.89[0.65-0.99]$ & & \\
\hline Bacil 2003 & $0.85[0.71-0.94]$ & $0.92[0.80-0.98]$ & & $=$ \\
\hline Bauer 2016 & $0.73[0.64-0.81]$ & $0.74[0.64-0.83]$ & & \\
\hline CakirMadenci 2014 & $0.75[0.69-0.81]$ & $0.79[0.74-0.83]$ & & 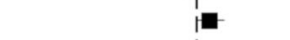 \\
\hline Endo 2012 & $0.86[0.78-0.92]$ & $0.79[0.67-0.87]$ & & 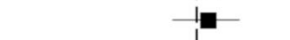 \\
\hline Enguix-Armada 2016 & $0.92[0.88-0.95]$ & $0.96[0.92-0.99]$ & - & 붕 \\
\hline Gibot 2004 & $0.83[0.69-0.92]$ & $0.69[0.49-0.85]$ & & $=i$ \\
\hline Godnic 2015 & $0.57[0.41-0.73]$ & $0.71[0.29-0.96]$ & $=$ & 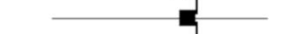 \\
\hline Klouche 2016 & $0.80[0.71-0.87]$ & $0.59[0.43-0.74]$ & & $=1$ \\
\hline Leli 2016 & $0.84[0.64-0.95]$ & $0.84[0.73-0.92]$ & $=-$ & $\frac{1}{1}=$ \\
\hline Miglietta 2015 & $0.86[0.75-0.93]$ & $0.83[0.69-0.93]$ & & \\
\hline Romualdo 2014 & $0.76[0.59-0.88]$ & $0.64[0.57-0.71]$ & - & \\
\hline Selberg 2000 & $0.86[0.65-0.97]$ & $0.55[0.23-0.83]$ & & \\
\hline Takahashi 2016 & $0.79[0.69-0.87]$ & $0.73[0.45-0.92]$ & & \\
\hline Ugarte 1999 & $0.68[0.58-0.76]$ & $0.61[0.49-0.72]$ & & $\square$ \\
\hline vanderGeest 2016 & $0.65[0.57-0.73]$ & $0.66[0.58-0.74]$ & - & - \\
\hline Wong 2013 & $0.88[0.82-0.93]$ & $0.64[0.55-0.72]$ & & \\
\hline Yang 2016 & $0.83[0.75-0.90]$ & $0.54[0.47-0.61]$ & & \\
\hline \multirow[t]{4}{*}{ COMBINED } & $0.80[0.75-0.84]$ & $0.75[0.67-0.81]$ & $\phi$ & $<$ \\
\hline & $Q=93.00, d f=17.00, p=0.00$ & $Q=132.11, d f=17.00, p=0.00$ & 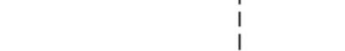 & 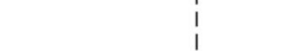 \\
\hline & $\mathrm{I} 2=81.72[74.01-89.43]$ & $12=87.13[82.21-92.05]$ & i & \\
\hline & & 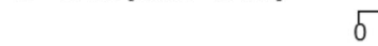 & $\begin{array}{llllll} & 1 & 1 & 1 & 1 & 1 \\
0.2 & 0.4 & 0.6 & 0.8 & 1.0 & 0\end{array}$ & $\begin{array}{lll}0.2 & 0.4 & 0.6\end{array}$ \\
\hline \multicolumn{5}{|l|}{ P-SEP } \\
\hline Author year & SENSITIVITY (95\% CI) & SPECIFICITY (95\% CI) & SENSITIVITY $(95 \% \mathrm{CI})$ & SPECIFICITY $(95 \% \mathrm{CI})$ \\
\hline Ali 2016 & $0.70[0.51-0.84]$ & $0.83[0.59-0.96]$ & $\square$ & $1=$ \\
\hline Behnes 2014 & $0.91[0.82-0.97]$ & $0.54[0.34-0.72]$ & + & $=1$ \\
\hline Behnes 2014 & $0.90[0.81-0.96]$ & $0.60[0.32-0.84]$ & $\perp$ & $=1$ \\
\hline CakirMadenci 2014 & $0.77[0.72-0.83]$ & $0.77[0.72-0.81]$ & $\mathbf{m}_{1}$ & ! \\
\hline Endo 2012 & $0.88[0.80-0.93]$ & $0.81[0.70-0.90]$ & - & $1=$ \\
\hline Enguix-Armada 2016 & $0.82[0.76-0.86]$ & $0.96[0.92-0.99]$ & $\Rightarrow$ & $=$ \\
\hline Godnic 2015 & $0.85[0.70-0.94]$ & $0.57[0.18-0.90]$ & 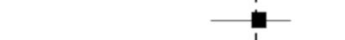 & $=1$ \\
\hline Klouche 2016 & $0.90[0.82-0.95]$ & $0.55[0.39-0.70]$ & $\frac{1}{1}=$ & $\square$ \\
\hline Leli 2016 & $0.88[0.69-0.97]$ & $0.72[0.59-0.82]$ & 1 & 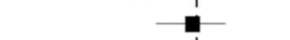 \\
\hline Romualdo 2014 & $0.81[0.65-0.92]$ & $0.63[0.56-0.70]$ & + & $\boldsymbol{- 1}_{1}^{1}$ \\
\hline Takahashi 2016 & $0.73[0.62-0.82]$ & $0.60[0.32-0.84]$ & -1 & $\begin{array}{ll}-1 \\
1\end{array}$ \\
\hline \multirow[t]{4}{*}{ COMBINED } & $0.84[0.80-0.88]$ & $0.73[0.61-0.82]$ & $\phi$ & $\phi$ \\
\hline & $Q=26.60, d f=10.00, p=0.00$ & $Q=75.16, d f=10.00, p=0.00$ & $i$ & i \\
\hline & $12=62.41[37.85-86.97]$ & $12=86.69[80.04-93.35]$ & 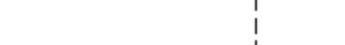 & \\
\hline & & 0 & $\begin{array}{llllll}1 & 1 & 1 & 1 & 1 & 1 \\
0.2 & 0.4 & 0.6 & 0.8 & 1.0 & 0\end{array}$ & $\begin{array}{lllll}0.2 & 0.4 & 0.6 & 0.8 & 1.0\end{array}$ \\
\hline
\end{tabular}

was downgraded by one level (from high to moderate). Furthermore, with the substantial heterogeneities among pooled estimates of the sensitivity and specificity in included studies, and because the source of heterogeneities could not be fully explained by the results of our sensitivity analysis, the quality of evidence of the outcomes was again downgraded by one level (from moderate to low). We found no serious indirectness and imprecision. Finally, the quality of the body of evidence supporting PCT and P-SEP for the diagnosis of infection were both graded as "low" for true positive, false negative, false positive, and true negative. Consequently, we graded the overall quality of evidence as "low."

\section{Discussion}

\section{Summary of the main results}

On the basis of the pre-defined protocol [17], the present meta-analysis and systematic review, which included 19 studies from several regions of the world, assessed the diagnostic accuracy of the index tests in participants with established infection in the critical care setting. To the best of our knowledge, this is the first study using appropriate methodologies and quality assessment tools, which provide evidence that there is no difference in the diagnostic performance of PCT and P-SEP in critically ill patients. Analyses of 


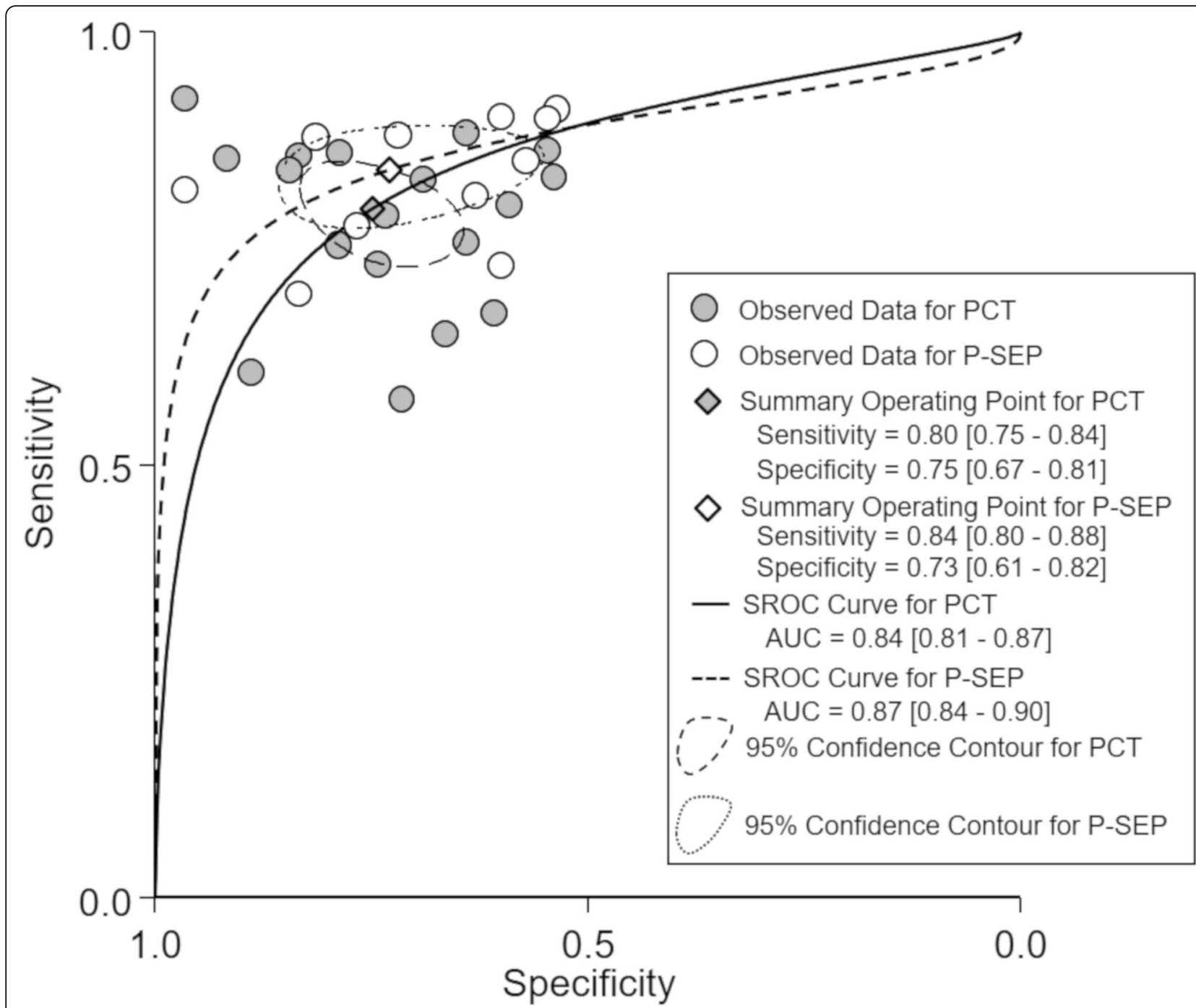

Fig. 4 Summary ROC curves of PCT (the solid line) and P-SEP (the dashed line) for the detection of infection. Each pair of points represents the pair of sensitivity and specificity for each evaluation. PCT, procalcitonin; P-SEP, presepsin. The overall diagnostic accuracy of PCT and P-SEP for infection was moderate and comparable

AUROC revealed AUC values of 0.84 for PCT and 0.87 for P-SEP with modest sensitivity and specificity. Positive and negative LRs for both biomarkers were sufficiently relevant as additional diagnostic tools in cases of infection, which were often indistinguishable from non-infectious disorders in critically ill patients.

Our sensitivity analysis suggested that several factors might have been responsible for the substantial heterogeneity across included studies. There were no obvious threshold effects for both PCT and P-SEP, partly because almost all included studies claimed that in each dataset, the post-specified cutoff threshold calculated by ROC analyses maximizes the diagnostic performance of either biomarker.

\section{Roles of procalcitonin and presepsin in the diagnosis of} sepsis

Given that the SSC guideline emphasizes early diagnosis to improve the clinical outcomes in sepsis [3], developing diagnostic strategies for infection is still required for accurate bedside diagnosis of infections. Although PCT has been widely reported to be an optimal biomarker in the diagnosis of sepsis $[38,39]$, more recent studies have produced conflicting results [4-6]. P-SEP, which is released into circulation after the activation of the proinflammatory signaling cascade upon contact with infectious agents [40], is emerging as a novel circulating marker for sepsis [9]. However, the clinical value of these biomarkers, independently or in combination, is still at investigative stages. Indeed, there are limited meta-analyses and systematic reviews comparing the 


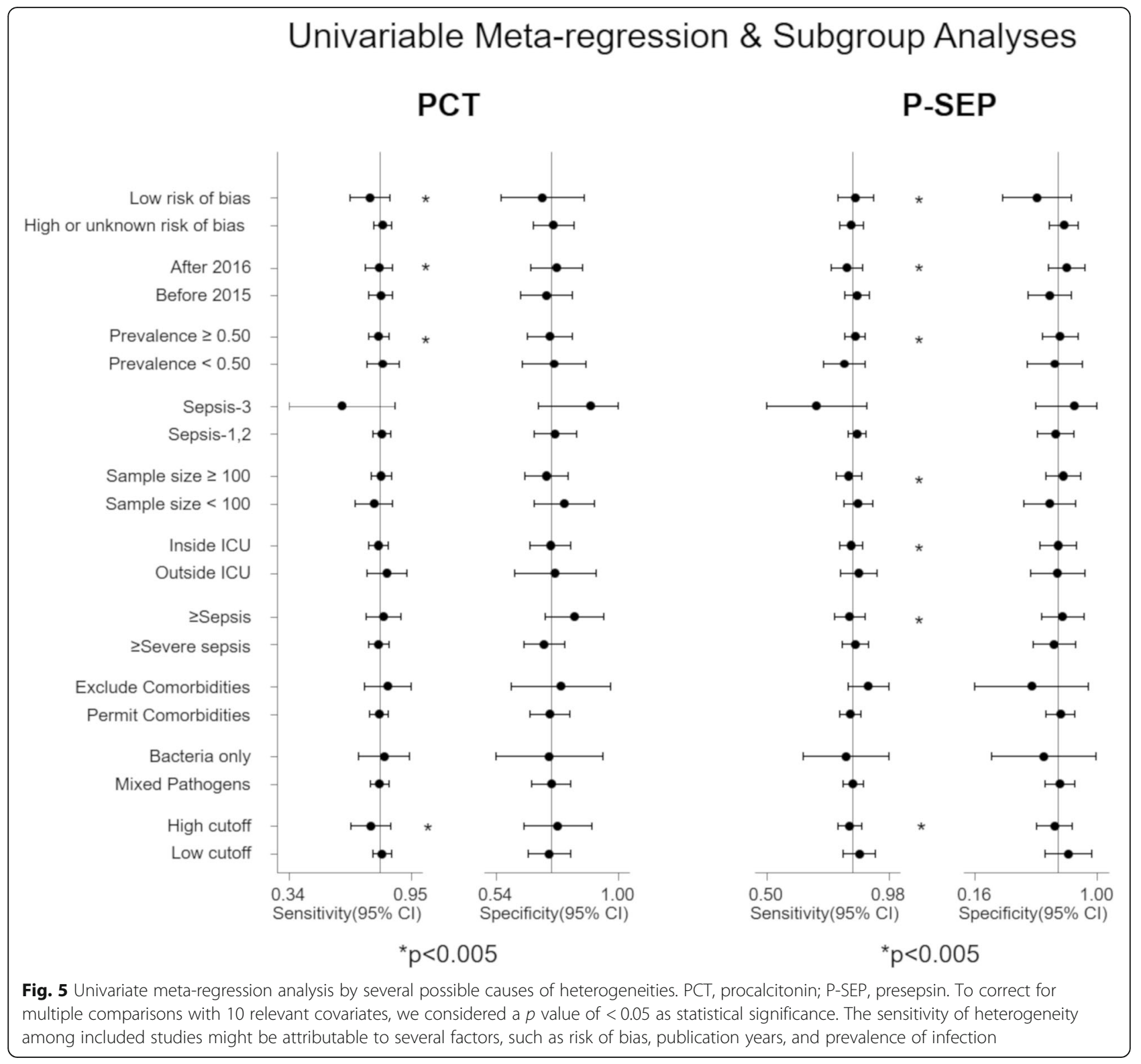

prognostic performance of P-SEP with PCT for the diagnosis of early-stage sepsis in critically ill patients. Thus, there is a lack of evidence to suggest the relevance of the triaging for these tests. Besides, it is still unclear whether testing for these biomarkers is an addition to the existing tests or a replacement, whether partial or complete.

\section{Quality of the evidence}

The quality of the body of evidence supporting PCT and P-SEP for the diagnosis of infection was judged as "low" for both markers. As almost all included studies did not pre-specify a clear cutoff threshold of PCT and P-SEP for a positive diagnosis (thus indicating an unclear or high risk of index test interpretation bias), we downgraded the quality of evidence by one level for the risk of bias. Consequently, we suggested the measurements of PCT and P-SEP as an optional diagnostic tool for infection and sepsis in critically ill patients. However, further researches are likely to have an important impact on our findings, which may result in changes to the recommendation.

\section{Strength of the review}

Several methodological strengths have enhanced the validity and applicability of our findings. This systematic review and meta-analysis included: (1) any study that measured PCT or P-SEP levels in 


\section{Deeks' Funnel Plot Asymmetry Test}
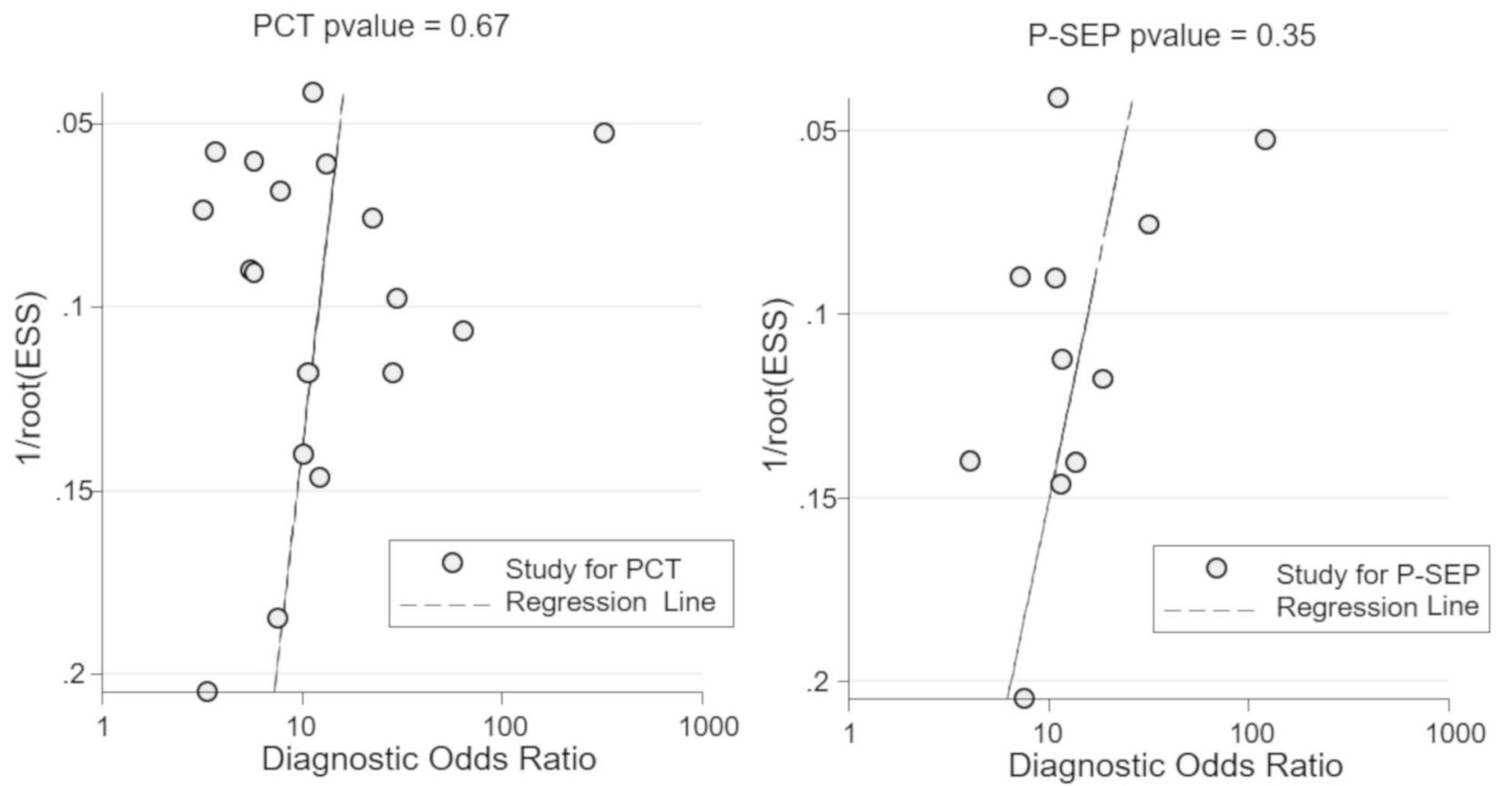

Fig. 6 Deeks' funnel plot to estimate the presence of publication bias. PCT, procalcitonin; P-SEP, presepsin; ESS, effective sample size. We detected no evidence of publication bias (PCT: $p=0.67$; P-SEP: $p=0.35$ )

critically ill adult patients with suspected sepsis, in whom the confirmation of sepsis was by clinical diagnosis or by microbiological confirmation of infection in cultures, or both; (2) comprehensive systemic search without any language restriction to the electronic searches (including 4203 published studies); (3) main results were discussed both by direct comparison and by subgroup analyses; (4) detailed subgroup analyses were performed to solve the heterogeneity concerns; and (5) quality of DTA evidence was rated through a transparent and structured process based on the GRADE approach.

\section{Agreements and disagreements with other studies}

Recently, one meta-analysis comparing P-SEP with other biomarkers (PCT and C-reactive protein) reported that P-SEP has similar diagnostic accuracy as PCT or C-reactive protein [41]. The most important feature distinguishing our analysis from this previous meta-analysis is that we focused only on studies evaluating participants with critical illnesses, such as acute respiratory distress syndrome and sepsis, but not healthy volunteers. The former study had high heterogeneity likely because it included normal healthy volunteers as controls. Thus, it should be interpreted more cautiously. As they reported, methods, to distinguish sepsis from non-infectious causes of inflammation, are necessary in clinical situations [41].

\section{Limitations of the review}

This study has several limitations. First, the microbiological approaches used for the definitive diagnosis of infection varied from one study to another; therefore, some degree of misclassification bias might have existed. Second, most included studies did not report the pre-specified cutoff thresholds for the biomarkers, which might have increased the risk of bias. Finally, since there was insufficient number of data available, we could not compare the bacterial, viral, and fungal infection population groups only. The usefulness of PCT and P-SEP in viral and fungal infection groups remains unknown.

\section{Conclusion}

Our meta-analysis suggests that both PCT and P-SEP are helpful biomarkers for the early 
Table 2 GRADE evidence profile to determine the accuracy of PCT and P-SEP when used to diagnose bacterial infection in adult critically ill patients

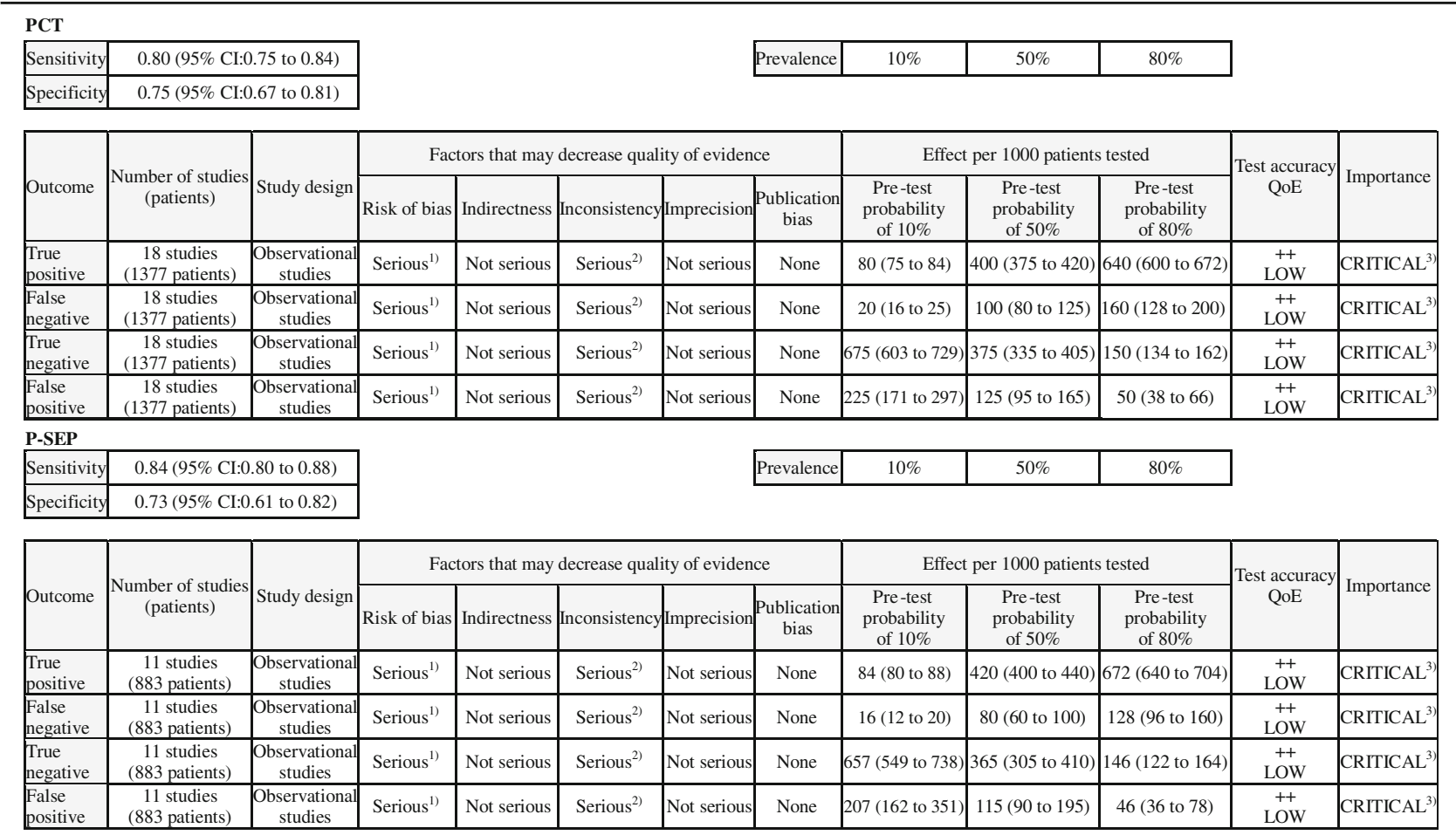

The GRADE approach results in an assessment of the quality of a body of evidence in one of four grades: high, moderate, low, or very low. For each outcome, the quality of evidence started at high, were downgraded by one level when there was a serious issue identified, and were downgraded by two levels when there was a very serious issue identified in each factor to judge the quality of evidence PCT procalcitonin, P-SEP presepsin, QoE quality of evidence

${ }^{1)}$ We downgraded all outcomes for risk of bias because all of the included studies presented an unclear or high risk of index test interpretation bias

${ }^{2)}$ We downgraded all outcomes for inconsistency because there were substantial heterogeneities among pooled results of sensitivity and specificity

${ }^{3)}$ We ranked the importance of all the four outcomes as critical

diagnosis of sepsis in critically ill adult patients. However, considering the need to avoid misdiagnosis or delayed diagnosis, the use of PCT or P-SEP tests in combination with other clinical modalities for sepsis diagnosis is recommended to improve diagnostic accuracy and patient outcomes.

\section{Additional files}

Additional file 1: Figure S1. Fagan's nomogram of PCT and P-SEP to calculate the positive/negative post-test probabilities of infection. PCT, procalcitonin; P-SEP, presepsin, LR, likelihood ratio. (TIF $2035 \mathrm{~kb}$ )

Additional file 2: Direct comparison by univariate meta-regression analysis. Direct comparison by univariate meta-regression analysis. PCT, procalcitonin; P-SEP, presepsin. In any subgroup, we found no statistically significant differences in pooled sensitivities and specificities between PCT and P-SEP. (DOCX $22 \mathrm{~kb})$

\section{Abbreviations}

AUROC: Area under ROC; Cl: Confidence interval; DTA: Diagnostic test accuracy; GRADE: Grading of Recommendations Assessment, Development, and Evaluation; ICU: Intensive care unit; LR: Likelihood ratio; MESH: Medical Subject Heading; PCT: Procalcitonin; PRISMA: Preferred Reporting Items for Systematic Reviews and Meta-Analyses; P-SEP: Presepsin; QUADAS-2: Quality
Assessment of Diagnostic Accuracy Studies; ROC: Receiver operating characteristic; SSC: Surviving Sepsis Campaign

\section{Acknowledgements}

We thank all members of the Japanese 2016 Clinical Practice Guidelines for Management of Sepsis and Septic Shock (J-SSCG2016) committee.

Funding

None

Availability of data and materials

The datasets are available from the corresponding author on reasonable request.

\section{Authors' contributions}

YK and KH contributed to the study design; acquisition, analysis, and interpretation of the data; and drafting of the manuscript. YU played an important role in the analysis of the data and helped to draft the manuscript. YH contributed to the study design and data acquisition. AM exerted a major impact on the interpretation of data and critical appraisal of the manuscript. KY conceived and designed this study; contributed to the acquisition, analysis, and interpretation of the data; and was responsible for drafting, editing, and submission of the manuscript. All authors read and approved the final manuscript.

Ethics approval and consent to participate Not applicable. 


\section{Consent for publication}

Not applicable.

\section{Competing interests}

The authors declare that they have no competing interests.

\section{Publisher's Note}

Springer Nature remains neutral with regard to jurisdictional claims in published maps and institutional affiliations.

\section{Author details}

'Department of Emergency and Critical Care Medicine, Juntendo University Urayasu Hospital, 2-1-1 Tomioka, Urayasu, Chiba 279-0021, Japan. ${ }^{2}$ Department of Traumatology and Acute Critical Medicine, Osaka University Graduate School of Medicine, 2-15 Yamadaoka, Suita, Osaka 565-0871, Japan. ${ }^{3}$ Department of Emergency and Critical Care Medicine, Keio University School of Medicine, 35 Shinanomachi, Shinjuku-ku, Tokyo 160-8582, Japan. ${ }^{4}$ Department of Anesthesiology and Critical Care Medicine, Fujita Health University School of Medicine, 1-98 Dengakugakubo, Kutsukakecho, Toyoake, Aichi 470-1192, Japan. ${ }^{5}$ Department of Gastroenterology and Hematology, Hirosaki University Graduate School of Medicine, 1-bunkyocho, Hirosaki, Aomori 036-8560, Japan. ${ }^{6}$ Division of Trauma and Surgical Critical Care, Osaka General Medical Center, 3-1-56 Bandai-Higashi, Sumiyoshi-ku, Osaka 558-8558, Japan.

\section{Received: 27 December 2018 Accepted: 21 March 2019} Published online: 15 April 2019

\section{References}

1. Singer M, Deutschman CS, Seymour CW, Shankar-Hari M, Annane D, Bauer $M$, et al. The third international consensus definitions for sepsis and septic shock (Sepsis-3). JAMA. 2016:315:801-10.

2. Fleischmann C, Scherag A, Adhikari NK, Hartog CS, Tsaganos T, Schlattmann P, Angus DC, Reinhart K; International Forum of Acute Care Trialists. Assessment of global incidence and mortality of hospitaltreated Sepsis. Current estimates and limitations. Am J Respir Crit Care Med 2016;193(3):259-272.

3. Rhodes A, Evans LE, Alhazzani W, Levy MM, Antonelli M, Ferrer R, Kumar A, Sevransky JE, Sprung CL, Nunnally ME, Rochwerg B, Rubenfeld GD, Angus DC, Annane D, Beale RJ, Bellinghan GJ, Bernard GR, Chiche JD, Coopersmith C, De Backer DP, French CJ, Fujishima S, Gerlach H, Hidalgo JL, Hollenberg SM, Jones AE, Karnad DR, Kleinpell RM, Koh Y, Lisboa TC, Machado FR, Marini JJ, Marshall JC, Mazuski JE, McIntyre LA, McLean AS, Mehta S, Moreno RP, Myburgh J, Navalesi P, Nishida O, Osborn TM, Perner A, Plunkett CM, Ranieri M, Schorr CA, Seckel MA, Seymour CW, Shieh L, Shukri KA, Simpson SQ, Singer M, Thompson BT, Townsend SR, Van der Poll T, Vincent JL, Wiersinga WJ, Zimmerman JL, Dellinger RP. Surviving sepsis campaign: international guidelines for management of sepsis and septic shock: 2016. Crit Care Med. 2017:45(3):486-552.

4. Tang BM, Eslick GD, Craig JC, McLean AS. Accuracy of procalcitonin for sepsis diagnosis in critically ill patients: systematic review and meta-analysis. Lancet Infect Dis. 2007;7(3):210-7.

5. Wacker C, Prkno A, Brunkhorst FM, Schlattmann P. Procalcitonin as a diagnostic marker for sepsis: a systematic review and meta-analysis. Lancet Infect Dis. 2013;13(5):426-35.

6. Hoeboer SH, van der Geest PJ, Nieboer D, Groeneveld AB. The diagnostic accuracy of procalcitonin for bacteraemia: a systematic review and metaanalysis. Clin Microbiol Infect. 2015;21(5):474-81.

7. Yaegashi Y, Shirakawa K, Sato N, Suzuki Y, Kojika M, Imai S, Takahashi G, Miyata M, Furusako S, Endo S. Evaluation of a newly identified soluble CD14 subtype as a marker for sepsis. J Infect Chemother. 2005:11(5):234-8.

8. Shirakawa K, Naitou K, Hirose J, Takahashi T, Furusako S. Presepsin (sCD14ST): development and evaluation of one-step ELISA with a new standard that is similar to the form of presepsin in septic patients. Clin Chem Lab Med. 2011:49(5):937-9.

9. Shozushima T, Takahashi G, Matsumoto N, Kojika M, Okamura Y, Endo S. Usefulness of presepsin (SCD14-ST) measurements as a marker for the diagnosis and severity of sepsis that satisfied diagnostic criteria of systemic inflammatory response syndrome. J Infect Chemother. 2011;17(6):764-9.
10. Okamura Y, Yokoi H. Development of a point-of-care assay system for measurement of presepsin (sCD14-ST). Clin Chim Acta. 2011;412(23-24):2157-61.

11. Endo S, Suzuki $Y$, Takahashi G, Shozushima T, Ishikura H, Murai A, Nishida T, Irie $Y$, Miura M, Iguchi H, Fukui Y, Tanaka K, Nojima T, Okamura Y. Usefulness of presepsin in the diagnosis of sepsis in a multicenter prospective study. J Infect Chemother. 2012;18(6):891-7.

12. Moher D, Liberati A, Tetzlaff J, Altman DG, PRISMA Group. Preferred reporting items for systematic reviews and meta-analyses: the PRISMA statement. Open Med. 2009;3:e123-30.

13. Liberati A, Altman DG, Tetzlaff J, Mulrow C, Gøtzsche PC, loannidis JP, Clarke M, Devereaux PJ, Kleijnen J, Moher D. The PRISMA statement for reporting systematic reviews and meta-analyses of studies that evaluate health care interventions: explanation and elaboration. J Clin Epidemiol. 2009;62:e1-34

14. Moher D, Shamseer L, Clarke M, Ghersi D, Liberati A, Petticrew M, Shekelle P, Stewart LA, PRISMA-P Group. Preferred reporting items for systematic review and meta-analysis protocols (PRISMA-P) 2015 statement. Syst Rev. 2015;4(1)

15. Stroup DF, Berlin JA, Morton SC, Olkin I, Williamson GD, Rennie D, Moher D, Becker BJ, Sipe TA, Thacker SB. Meta-analysis of observational studies in epidemiology: a proposal for reporting. Meta-analysis Of Observational Studies in Epidemiology (MOOSE) group. JAMA. 2000;283:2008-12.

16. Leeflang MM, Deeks JJ, Gatsonis C, Bossuyt PM; Cochrane Diagnostic Test Accuracy Working Group. Systematic reviews of diagnostic test accuracy. Ann Intern Med 2008;149: 889-897.

17. Hayashida K, Kondo Y, Hara Y, Aihara M, Yamakawa K. Head-to-head comparison of procalcitonin and presepsin for the diagnosis of sepsis in critically ill adult patients: a protocol for a systematic review and metaanalysis. BMJ Open. 2017 Mar 6;7(3):e014305

18. Levy MM, Fink MP, Marshall JC, Abraham E, Angus D, Cook D, et al. 2001 SCCM/ESICM/ACCP/ATS/SIS international sepsis definitions conference. Crit Care Med. 2003:31:1250e6.

19. Whiting PF, Rutjes AW, Westwood ME, Mallett S, Deeks JJ, Reitsma JB, Leeflang MM, Sterne JA, Bossuyt PM; QUADAS-2 Group. QUADAS-2: a revised tool for the quality assessment of diagnostic accuracy studies. Ann Intern Med 2011:155:529-536.

20. Hsu J, Bro ek JL, Terracciano L, Kreis J, Compalati E, Stein AT, Fiocchi A, Schünemann HJ. Application of GRADE: making evidence-based recommendations about diagnostic tests in clinical practice guidelines. Implement Sci. 2011;6:62.

21. Ali FT, Ali MA, Elnakeeb MM, Bendary HN. Presepsin is an early monitoring biomarker for predicting clinical outcome in patients with sepsis. Clin Chim Acta. 2016:460:93-101.

22. Balcl C, Sungurtekin H, Gürses E, Sungurtekin U, Kaptanoglu B. Usefulness of procalcitonin for diagnosis of sepsis in the intensive care unit. Crit Care. 2003;7(1):85-90

23. Bauer PR, Kashyap R, League SC, Park JG, Block DR, Baumann NA Algeciras-Schimnich A, Jenkins SM, Smith CY, Gajic O, Abraham RS. Diagnostic accuracy and clinical relevance of an inflammatory biomarker panel for sepsis in adult critically ill patients. Diagn Microbiol Infect Dis. 2016:84(2):175-80.

24. Behnes M, Bertsch T, Lepiorz D, Lang S, Trinkmann F, Brueckmann M, Borggrefe M, Hoffmann U. Diagnostic and prognostic utility of soluble CD 14 subtype (presepsin) for severe sepsis and septic shock during the first week of intensive care treatment. Crit Care. 2014;18(5):507.

25. Cakır Madenci Ö, Yakupoğlu S, Benzonana N, Yücel N, Akbaba D, Orçun Kaptanağası A. Evaluation of soluble CD14 subtype (presepsin) in burn sepsis. Burns. 2014:40(4):664-9.

26. Enguix-Armada A, Escobar-Conesa R, García-De La Torre A, De La TorrePrados MV. Usefulness of several biomarkers in the management of septic patients: C-reactive protein, procalcitonin, presepsin and mid-regional proadrenomedullin. Clin Chem Lab Med. 2016:54(1):163-8.

27. Gibot S, Kolopp-Sarda MN, Béné MC, Cravoisy A, Levy B, Faure GC, Bollaert PE. Plasma level of a triggering receptor expressed on myeloid cells-1: its diagnostic accuracy in patients with suspected sepsis. Ann Intern Med. 2004:141(1):9-15.

28. Godnic M, Stubljar D, Skvarc M, Jukic T. Diagnostic and prognostic value of sCD14-ST--presepsin for patients admitted to hospital intensive care unit (ICU). Wien Klin Wochenschr. 2015;127(13-14):521-7.

29. Klouche K, Cristol JP, Devin J, Gilles V, Kuster N, Larcher R, Amigues L, Corne $\mathrm{P}$, Jonquet O, Dupuy AM. Diagnostic and prognostic value of soluble CD14 
subtype (Presepsin) for sepsis and community-acquired pneumonia in ICU patients. Ann Intensive Care. 2016;6(1):59.

30. Leli C, Ferranti M, Marrano U, Al Dhahab ZS, Bozza S, Cenci E, Mencacci A. Diagnostic accuracy of presepsin (sCD14-ST) and procalcitonin for prediction of bacteraemia and bacterial DNAaemia in patients with suspected sepsis. J Med Microbiol. 2016;65(8):713-9.

31. Miglietta F, Faneschi ML, Lobreglio G, Palumbo C, Rizzo A, Cucurachi M, Portaccio G, Guerra F, Pizzolante M. Procalcitonin, C-reactive protein and serum lactate dehydrogenase in the diagnosis of bacterial sepsis, SIRS and systemic candidiasis. Infez Med. 2015;23(3):230-7.

32. Selberg O, Hecker H, Martin M, Klos A, Bautsch W, Köhl J. Discrimination of sepsis and systemic inflammatory response syndrome by determination of circulating plasma concentrations of procalcitonin, protein complement 3a, and interleukin-6. Crit Care Med. 2000;28(8):2793-8.

33. Takahashi W, Nakada TA, Yazaki M, Oda S. Interleukin-6 levels act as a diagnostic marker for infection and a prognostic marker in patients with organ dysfunction in intensive care units. Shock. 2016;46(3):254-60.

34. Ugarte H, Silva E, Mercan D, De Mendonça A, Vincent JL. Procalcitonin used as a marker of infection in the intensive care unit. Crit Care Med. 1999;27(3):498-504.

35. van der Geest PJ, Mohseni M, Linssen J, Duran S, de Jonge R, Groeneveld $A B$. The intensive care infection score - a novel marker for the prediction of infection and its severity. Crit Care. 2016;20(1):180.

36. Wong HR, Lindsell CJ, Lahni P, Hart KW, Gibot S. Interleukin 27 as a sepsis diagnostic biomarker in critically ill adults. Shock. 2013;40(5):382-6.

37. Yang Y, Xie J, Guo F, Longhini F, Gao Z, Huang Y, Qiu H. Combination of Creactive protein, procalcitonin and sepsis-related organ failure score for the diagnosis of sepsis in critical patients. Ann Intensive Care. 2016;6(1):51.

38. Assicot M, Gendrel D, Carsin H, Raymond J, Guilbaud J, Bohuon C. High serum procalcitonin concentrations in patients with sepsis and infection. Lancet. 1993;341(8844):515-8.

39. Brunkhorst FM, Wegscheider K, Forycki ZF, Brunkhorst R. Procalcitonin for early diagnosis and differentiation of SIRS, sepsis, severe sepsis, and septic shock. Intensive Care Med. 2000;26(Suppl 2):S148-52. https://doi.org/10. 1007/BF02900728.

40. Wright SD, Ramos RA, Tobias PS, Ulevitch RJ, Mathison JC. CD14, a receptor for complexes of lipopolysaccharide (LPS) and LPS binding protein. Science. 1990;249(4975):1431-3.

41. Wu CC, Lan HM, Han ST, Chaou CH, Yeh CF, Liu SH, Li CH, Blaney GN 3rd, Liu ZY, Chen KF. Comparison of diagnostic accuracy in sepsis between presepsin, procalcitonin, and C-reactive protein: a systematic review and meta-analysis. Ann Intensive Care. 2017;7(1):91.

Ready to submit your research? Choose BMC and benefit from:

- fast, convenient online submission

- thorough peer review by experienced researchers in your field

- rapid publication on acceptance

- support for research data, including large and complex data types

- gold Open Access which fosters wider collaboration and increased citations

- maximum visibility for your research: over $100 \mathrm{M}$ website views per year

At BMC, research is always in progress.

Learn more biomedcentral.com/submissions 